\title{
Liquefaction Mitigation Using Bentonite Suspensions
}

\author{
C. S. El Mohtar, A.M.ASCE'; A. Bobet, M.ASCE'; M. C. Santagata, A.M.ASCE'; \\ V. P. Drnevich, Dist.M.ASCE${ }^{4}$; and C. T. Johnston ${ }^{5}$
}

\begin{abstract}
Ottawa sand specimens premixed with 0,3 , and $5 \%$ bentonite by dry mass of sand were tested under undrained static and cyclic loading to investigate the effects of bentonite on the static and cyclic shear strength of the sand. The results show that allowing the bentonite to hydrate within the sand pore space increases the cyclic resistance of the sand. For the same skeleton relative density and cyclic stress ratio, cyclic tests on specimens with sufficient hydration times showed a significant increase in the number of cycles required for liquefaction compared with clean sand. When the specimens were allowed an extended postconsolidation aging period, the cyclic resistance increased further. Resonant column and cyclic triaxial tests showed that this is a result of the delay in the generation of excess pore pressure in the presence of the bentonite suspension in the pore space. The improvement in cyclic behavior does not occur at the expense of the static resistance of the soil under working loads because undrained static triaxial tests on specimens with bentonite showed only a minor decrease in the small-strain internal friction angle compared with the clean sand, while the critical-state internal friction angle remained unchanged. To address the need to deliver the bentonite suspension in a sand deposit, a method for engineering the rheology of concentrated bentonite suspensions through the addition of sodium pyrophosphate (SPP) was developed. With the addition of $0.5 \%$ SPP by mass of clay, the viscosity of concentrated (10\%) bentonite dispersions dropped to a value that allowed delivery of the bentonite into the sand matrix through permeation. Over time, the bentonite suspension recovered the thixotropic properties that ensured its effectiveness in mitigating liquefaction. As a result, sand specimens permeated with $10 \%$ bentonite suspensions showed a large increase in liquefaction resistance. Changes in the rheological properties of the pore fluid with time also explain the increase with aging of the cyclic resistance of the sand-bentonite specimens. DOI: 10.1061/(ASCE)GT.19435606.0000865. (C) 2013 American Society of Civil Engineers.
\end{abstract}

CE Database subject headings: Soil liquefaction; Sand (soil type); Bentonite; Triaxial tests; Shear strength; Rheology.

Author keywords: Liquefaction; Mitigation; Bentonite suspensions; Cyclic triaxial tests; Shear strength; Rheological tests.

\section{Introduction}

Liquefaction includes all phenomena involving excessive deformations or movements as a result of transient or repeated disturbance of saturated cohesionless soils. In such soils, particularly fineto-medium sands or even finer nonplastic soils, undrained cyclic loading, which can occur during an earthquake, may produce excess pore pressures that reduce the effective stresses; liquefaction occurs when the effective stresses approach zero (Seed and Lee 1966). Liquefaction is an important cause of damage to the built environment during earthquakes. The state of practice on the liquefaction susceptibility of soils has been summarized by Seed et al. (1985) and Youd et al. (2001). The potential for a soil to liquefy is based on

\footnotetext{
${ }^{1}$ Assistant Professor, Dept. of Civil, Architectural and Environmental Engineering, Univ. of Texas at Austin, Austin, TX 78712 (corresponding author). E-mail: ElMohtar@mail.utexas.edu

${ }^{2}$ Professor, School of Civil Engineering, Purdue Univ., West Lafayette, IN 47907. E-mail: bobet@ecn.purdue.edu

${ }^{3}$ Associate Professor, School of Civil Engineering, Purdue Univ., West Lafayette, IN 47907. E-mail: mks@ @ purdue.edu

${ }^{4}$ Professor Emeritus, School of Civil Engineering, Purdue Univ., West Lafayette, IN 47907. E-mail: drnevich@purdue.edu

${ }^{5}$ Professor, Dept. of Agronomy, Purdue Univ., West Lafayette, IN 47907. E-mail: cliffjohnston@purdue.edu

Note. This manuscript was submitted on April 28, 2011; approved on November 15, 2012; published online on November 19, 2012. Discussion period open until January 1, 2014; separate discussions must be submitted for individual papers. This paper is part of the Journal of Geotechnical and Geoenvironmental Engineering, Vol. 139, No. 8, August 1, 2013. (c)ASCE, ISSN 1090-0241/2013/8-1369-1380/\$25.00.
}

the cyclic stress ratio (CSR), which is a measure of the shear demand on the soil produced by the earthquake, and the cyclic resistance ratio (CRR) that measures the shear strength of the soil. The CRR can be obtained from laboratory tests that simulate earthquake loading or, more often, because of the difficulties in retrieving intact samples of granular soils, from the results of field tests [standard penetration test (SPT), cone penetration test, Becker penetration test] and/or measurements of the shear-wave velocity $\left(V_{s}\right)$. The relative density, stress history, particle size, particle shape, and gradation of the sand, as well as the stress state and the nature of the cyclic loading, are critical factors that determine liquefaction susceptibility (Ishihara and Yasuda 1975; De Alba et al. 1976; Ishihara and Yamazaki 1980; Mohamad and Dobry 1983; Vaid and Chern 1983; Poulos et al. 1985).

For sands, there is a threshold strain level below which no liquefaction takes place regardless of the number of loading cycles (Drnevich and Richart 1970; Dobry et al. 1981). Observations in the field after earthquakes indicate that the presence of fines may increase the liquefaction resistance of cohesionless soils and much work has been done in the past years in the laboratory to explore this effect further. In such studies the beneficial effects of fines have not been always observed, and a review of the literature indicates that it is necessary to distinguish between the effects of nonplastic and plastic fines (e.g., Shen et al. 1977; Chang et al. 1982; Dezfulian 1982; Tronsco and Verdugo 1985; Kuerbis et al. 1988; Georgiannou et al. 1991; Law and Ling 1992; Finn et al. 1994; Koester 1994; Vaid 1994; Polito 1999; Thevanayagam et al. 2002; Polito and Martin 2003; Carraro et al. 2003). Instead, a clearer picture emerges from the literature with respect to the effect of plastic fines. There is general agreement that the liquefaction resistance of a soil increases 
with its plasticity index (PI). This is confirmed by laboratory results (Ishihara and Koseki 1989; Yasuda et al. 1994) and by field observations (Wang 1979; Seed et al. 1983; Tokimatsu and Yoshimi 1983; Ishihara 1993, 1996), and is reflected in recommendations for design such as those contained in the Chinese criterion (Wang 1979) and those provided by Ishihara and Koseki (1989) and Ishihara (1993), who propose increasing the CRR factor based on the PI for soils with PI $>10$.

The current practice for liquefaction mitigation may involve significant changes to the properties of the original soil under working loads either by densifying the soil or by chemically cementing it. In particular, for developed sites, liquefaction mitigation usually involves grouting or underpinning. In addition to jet grouting techniques (Martin and Olgun 2006; Olgun 2003; Spagnoli 2008), a new approach has been proposed for passive site mitigation using colloidal silica (Gallagher 2000; Gallagher and Mitchell 2002; Gallagher et al. 2007), where injection wells are installed at the site and natural or manufactured water flow is used to deliver the treatment to the desired areas. The approach to liquefaction mitigation proposed in this paper involves permeation of a bentonite suspension to replace the water in the pore spaces of the desired site (Haldavnekar et al. 2003; El Mohtar et al. 2008a; Rugg et al. 2011). Because of its small size and high plasticity, bentonite appears to be an attractive material to treat sands for liquefaction mitigation. Bentonite has the following additional advantages: (1) wide availability; (2) low cost; (3) large experience base in geotechnical engineering; and (4) lack of environmental contamination. This paper presents laboratory results of static triaxial, cyclic triaxial, resonant column, and permeation tests on sand specimens treated with a bentonite suspension to investigate the effects of the treatment on the cyclic resistance of the sand. A mechanism is proposed by which the bentonite affects the mechanical properties of the soil, and the method of delivering the bentonite into the sand medium is evaluated.

\section{Specimen Preparation}

The experimental work focused on the investigation of the mechanical behavior of clean sand and sand treated with 3 and 5\% bentonite (by dry mass of the sand) through resonant column tests, as well as through static and cyclic triaxial tests. Two series of tests were conducted. In the first series, the bentonite was introduced into the sand specimens by dry mixing the sand and bentonite before specimen preparation (referred to as wished in place bentonite). In the second series, the bentonite was introduced into the sand specimens by permeation. Most of the experiments were conducted using the wished in place preparation procedure. This was done to determine the fundamental behavior of sand-bentonite mixtures subjected to mechanical loading. In parallel, efforts were made to develop a treatment of the bentonite such that the viscosity of a concentrated bentonite suspension was initially decreased to facilitate permeation into the sand pores and was subsequently recovered after the bentonite was inside the pores of the sand. The second series of tests consisted of a limited number of cyclic triaxial tests to evaluate the success of the treatment by obtaining the number of cycles to liquefaction of sand specimens permeated with suspensions of chemically treated bentonite.

The sand used for the tests was Ottawa sand $\mathrm{C} 778$, a very uniform $\left(C_{u}=1.7\right)$, clean, fine-to-medium sand, with $2-5 \%$ nonplastic fines, specific gravity of $G_{s}=2.65$, and maximum and minimum void ratios equal to $0.78\left(e_{\max }\right)$ and $0.48\left(e_{\min }\right)$, respectively. The bentonite used was a commercial Wyoming sodium bentonite, manufactured by VOLCLAY, with at least $85 \%$ passing the No. 200 sieve, specific gravity of 2.65 , and liquid and plastic limits equal to 397 and $41 \%$, respectively. In addition, sodium pyrophosphate (SPP) was used to control the rheological properties of the bentonite suspensions. SPP decahydrated $\left(\mathrm{Na}_{4} \mathrm{P}_{2} \mathrm{O}_{7} \cdot 10 \mathrm{H}_{2} \mathrm{O}\right)$, which consists of two phosphate tetrahedral groups linked together through a common oxygen atom, was obtained from Sigma-Aldrich Chemicals.

The wished in place or dry-mix method consisted of dry mixing the sand and the corresponding percentage of bentonite (3 or $5 \%$ with respect to the dry weight of the sand) and air pluviating the mixture into a mold. Air pluviation consists of dropping soil particles through a funnel and tube into a mold. A series of tests using tubes with various diameters and lengths as well as adjusting the free drop height (elevation from the top of the sand to the bottom of the tube) was performed to achieve the desired specimen void ratio. For specimens with bentonite, the required amounts of sand and bentonite were placed in a cylindrical closed container $(15 \mathrm{~cm}$ in diameter and $30 \mathrm{~cm}$ in height) and mixed for $10 \mathrm{~min}$. The mixing consisted of hand shaking the container with its longer axis positioned in the horizontal direction to avoid segregation of the sand and bentonite. The soil (clean sand or sand with various amounts of bentonite) was then pluviated into a mold at the desired relative density.

Height and weight measurements at various stages of specimen preparation were taken to calculate the void ratio for various portions of the specimen to verify specimen uniformity. After completion of each test, the specimen was divided into three sections (top, center, and bottom) and the bentonite content was measured in each section. The measured bentonite contents were within $\pm 0.25 \%$ (by dry mass of sand) of the target bentonite content. All specimens were prepared at the same skeleton void ratio (Polito and Martin 2003; Yamamuro and Wood 2004). The skeleton void ratio is defined as the void ratio of the soil when all the bentonite is eliminated, and is representative of the state of the soil in the field prior to the bentonite treatment. All specimens were prepared at skeleton relative densities of $38 \pm 5 \%$. The minimum and maximum void ratios of the clean sand were used to calculate the skeleton relative density.

After pluviation, $\mathrm{CO}_{2}$ was flushed from the bottom of the specimen under low gradient followed by flushing with water, also at low gradient. The specimens were either subjected to back-pressure right after flushing or were allowed to hydrate before applying backpressure. In this preparation method, all drainage lines were dry at the beginning of the test. Having saturated lines would result in hydration of the bentonite near the top and bottom caps and would not allow for $\mathrm{CO}_{2}$ or water flushing. The time at which back-pressure was applied to the soil significantly affected the response of the specimens with bentonite (discussed subsequently herein). The specimen was then isotropically consolidated to the required confining stress, left undisturbed for a period of time, and tested.

Additional specimens of sand permeated with SPP-treated bentonite suspensions were prepared for cyclic triaxial tests. The specimen preparation followed a procedure similar to that of the dry-mix method, except that the specimens were made only of sand. The soil was pluviated into an external split mold and then flushed with $\mathrm{CO}_{2}$ and subsequently with water. Bentonite suspensions with various concentrations of SPP were permeated through the specimen from the bottom. Afterward, the permeated specimen was transferred to the triaxial cell for testing. As with the other tests, the specimen was then back-pressure saturated, consolidated to the required confining stress, left undisturbed for a period of time, and tested. In all undrained tests, the excess pore pressure was measured at the base of the specimen. More details on the preparation method of the permeated specimens can be found in El Mohtar (2008) and Rugg et al. (2011). 


\section{Results from Specimens Prepared Using the Dry-Mix Method}

\section{Hydration of Bentonite in the Pore Space}

Undrained cyclic tests were performed on specimens prepared with 0 (clean sand), 3 , and $5 \%$ bentonite (by mass of the sand) targeting a skeleton relative density in the $35-43 \%$ range, and isotropically consolidated to an effective stress of $100 \mathrm{kPa}$. The CSR ranged between 0.1 and 0.25 at a $1-\mathrm{Hz}$ frequency and was applied using an MTS Systems Corporation machine available in Purdue's Bechtel Geotechnical Laboratory. For the cyclic triaxial tests, the axial deformation, axial load, cell pressure, and excess pore pressure were monitored with a data collection rate of $20 \mathrm{~Hz}$, using an automated data acquisition system developed for this research using the LabVIEW software.

Figs. 1 and 2 show the results of the cyclic tests on two sand specimens with $5 \%$ bentonite, where cyclic shearing was started after different times from the start of the water flushing stage (54 and $84 \mathrm{~h}$ for the plots in Figs. 1 and 2, respectively). Fig. 1(a) shows the evolution of the deviatoric stress with the number of cycles, Fig. 1(b) is a plot of the effective confining stress with the number of cycles, and Fig. 1(c) shows the effective stress path followed by the specimen on a $p^{\prime}-q$ diagram. Fig. 1(b) indicates that with the initial cycles there was an increase in excess pore pressure; afterward, the effective confining stress decreased steadily until about 35 cycles. At

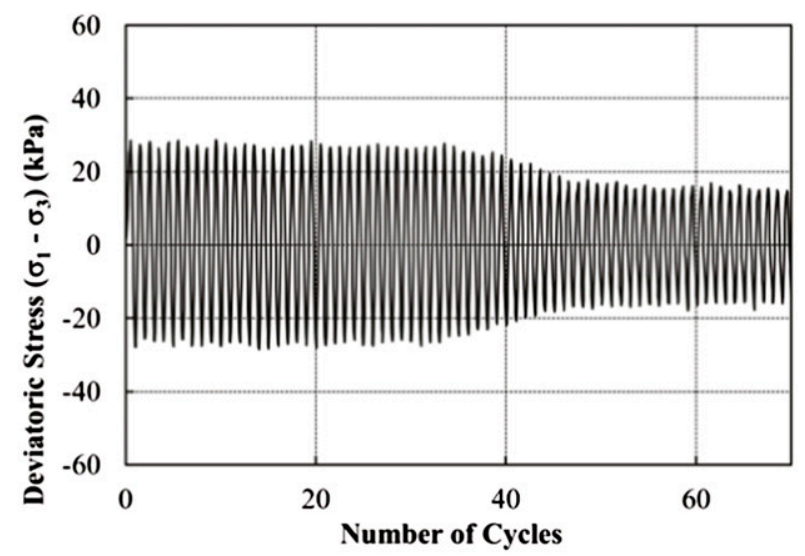

(a) Deviatoric stress

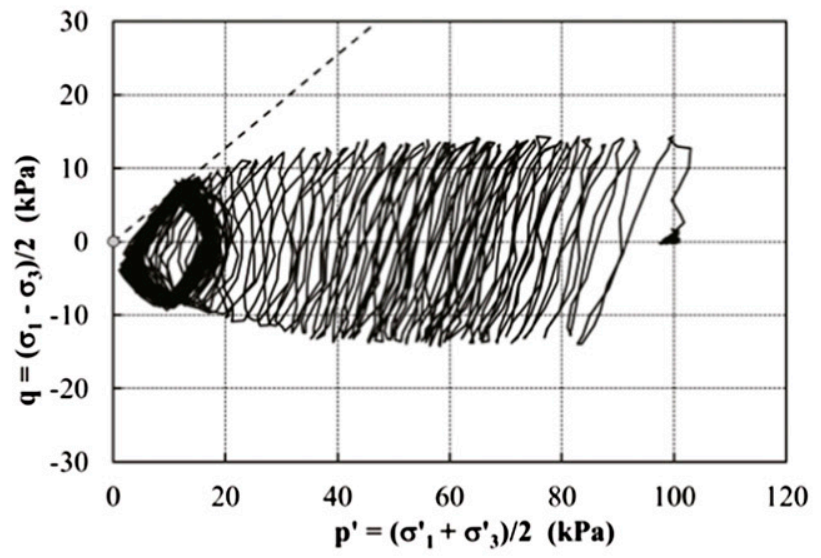

(c) p' - q Diagram this point, the effective confining stress decreased more rapidly until it was very small or zero and liquefaction occurred at 48 cycles. In this study, liquefaction is defined as either the loss of effective confining stress or $5 \%$ double-amplitude strain, whichever occurs in fewer cycles. At this point, the $p^{\prime}-q$ stress path touches the failure envelope of the material [presented by the dashed line in Fig. 1(c)]. Fig. 1(d) shows the excess pore pressure generated between cycles 23 and 28. In Fig. 1(d), the following two components of the excess pore pressure are shown: (1) the excess cyclic pore pressure $\left(U_{\text {cyclic }}\right)$, defined as the peak-to-peak magnitude of the excess pore pressure generated with each loading cycle; and (2) the excess mean pore pressure $\left(U_{\text {mean }}\right)$, defined as the average of the excess pore pressure value over a loading cycle. The buildup of $U_{\text {mean }}$ between consecutive cycles leads to the loss of lateral effective stress and liquefaction.

Fig. 2 shows the results of a cyclic test conducted on a specimen prepared following the same procedure as that of the test shown in Fig. 1; however, liquefaction did not occur. As shown in Fig. 2(a), the deviatoric stress remained constant throughout the test, indicating that the specimen remained intact. Fig. 2(b) is a plot of the effective confining stress with the number of cycles and shows an initial large generation of excess pore pressure, as indicated by the sharp decrease in effective confining stress. This phenomenon is also observed in the $p^{\prime}-q$ plot in Fig. 2(c), which shows that the mean effective stress, $p^{\prime}$, has been reduced with the number of cycles and the stress path has moved to the left toward the failure envelope.

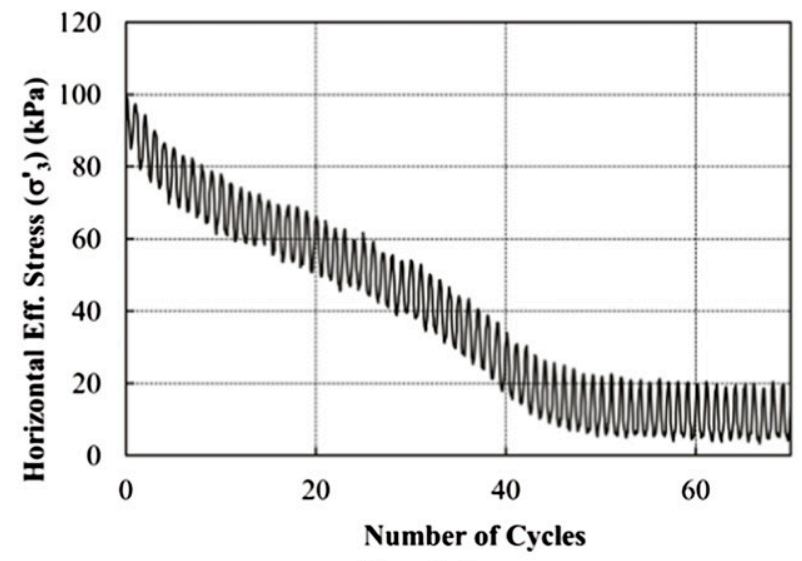

(b) Confining stress

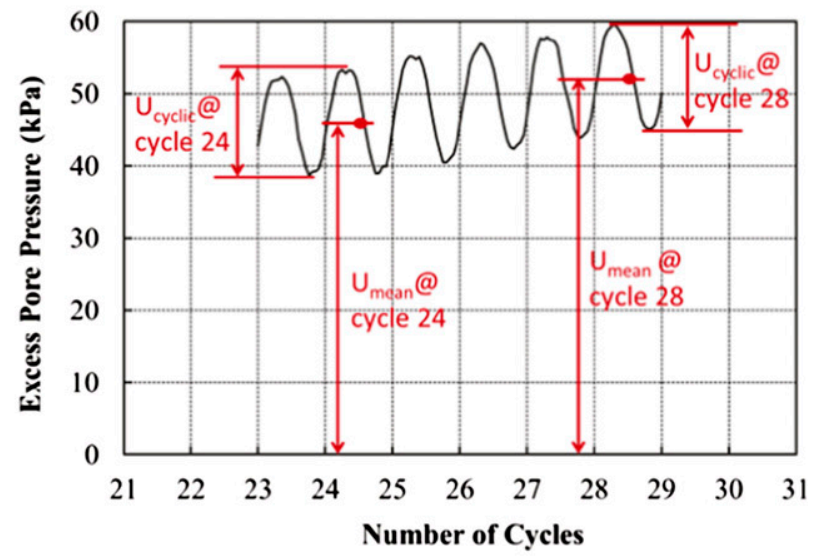

(d) $\mathrm{U}_{\text {cyclic }}$ and $\mathrm{U}_{\text {mean }}$

Fig. 1. Results of cyclic test on $5 \%$ bentonite specimen with CSR $=0.15$ (54 h from flushing with water to shearing): (a) deviatoric stress; (b) confining stress; (c) $p^{\prime}-q$ diagram; (d) $U_{\text {cyclic }}$ and $U_{\text {mean }}$ 


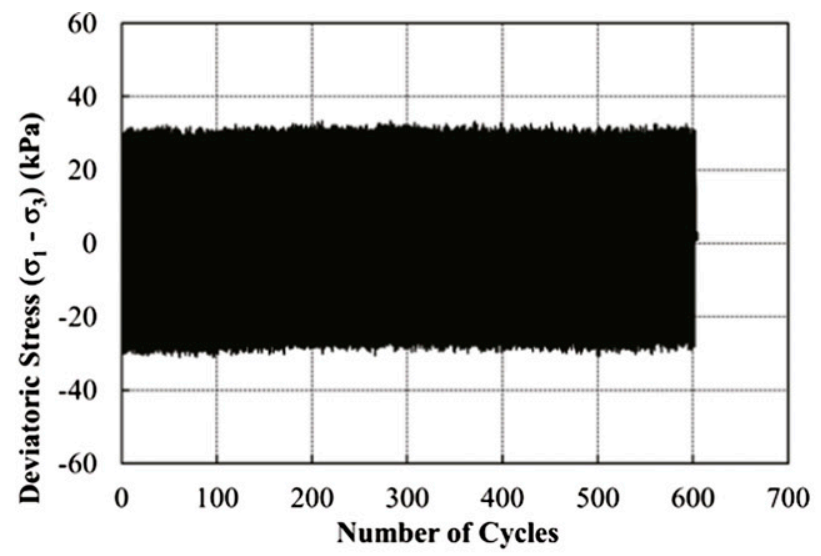

(a) Deviatoric stress

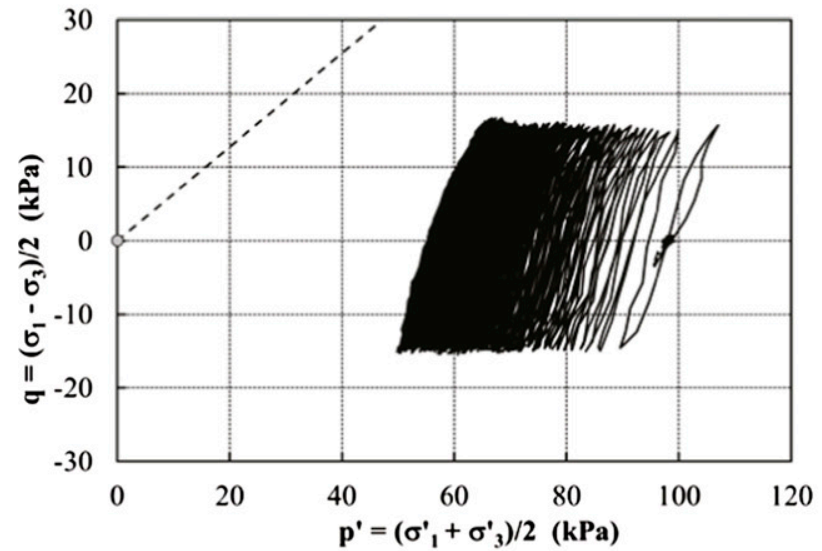

(c) p' - q Diagram

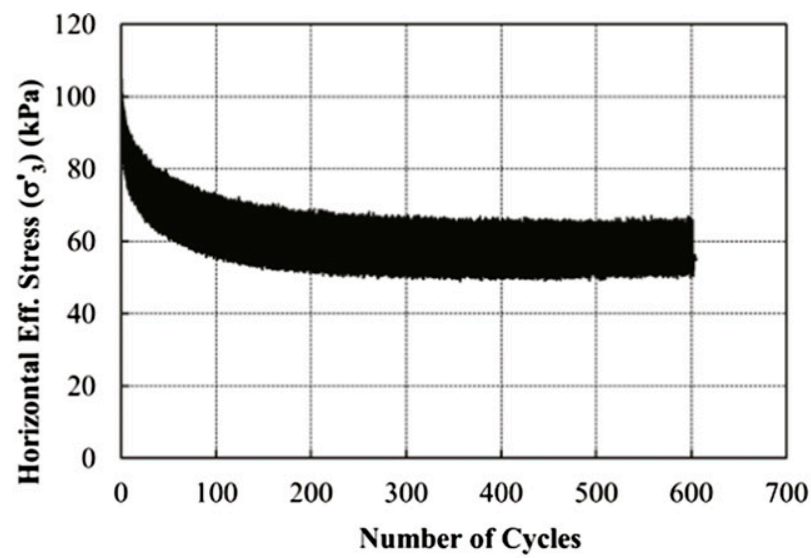

(b) Confining stress

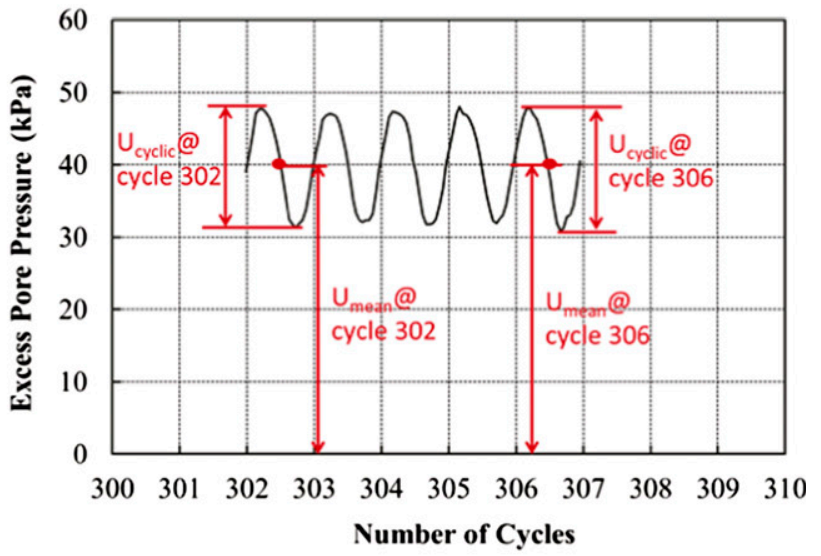

(d) $\mathrm{U}_{\text {cyclic }}$ and $\mathrm{U}_{\text {mean }}$

Fig. 2. Results of cyclic test on $5 \%$ Bentonite specimen with CSR $=0.15$ ( $84 \mathrm{~h}$ from flushing with water to shearing): (a) deviatoric stress; (b) confining stress; (c) $p^{\prime}-q$ diagram; (d) $U_{\text {cyclic }}$ and $U_{\text {mean }}$

Until this point, the behavior of the specimen was similar to that of Fig. 1, except that the loss of effective stresses occurred at a slower rate. At about 200 cycles, no additional excess pore pressure was generated. Fig. 2(d) shows $U_{\text {mean }}$ and $U_{\text {cyclic }}$ for Cycles 302-307. The data show that $U_{\text {mean }}$ remains constant for consecutive cycles, limiting the loss of the lateral effective stress and resulting in the specimen not liquefying even after 600 cycles.

The difference in behavior observed between the two tests (Figs. 1 and 2) can be ascribed to differences in the pore fluid, and in particular to the degree of gel structure developed in the bentonite suspension present in the pores. This is demonstrated by the results of a series of triaxial cyclic tests performed on identical $3 \%$ bentonitesand mixtures with a skeleton relative density of $35 \%$, all tested with a CSR of 0.15 , varying the hydration time (measured from the time when the specimen was flushed with water to the beginning of the cyclic shearing phase). Fig. 3 presents the results of these tests and shows that the cyclic resistance increased with hydration time up to $100 \mathrm{~h}$, after which the hydration time effect was minimal.

When given access to water, the bentonite in the pores of the sand skeleton requires a minimum time to hydrate and swell. Additionally, Komine and Ogata (2003) showed that the swelling pressures of sand-bentonite mixtures with low bentonite content are as low as a few kilopascals. Both observations suggest that the hydration time, time of application, and magnitude of the backpressure during saturation affect the swelling mechanisms. The first point is supported by the results presented in Fig. 3, which show that testing shortly after flushing yields no improvement

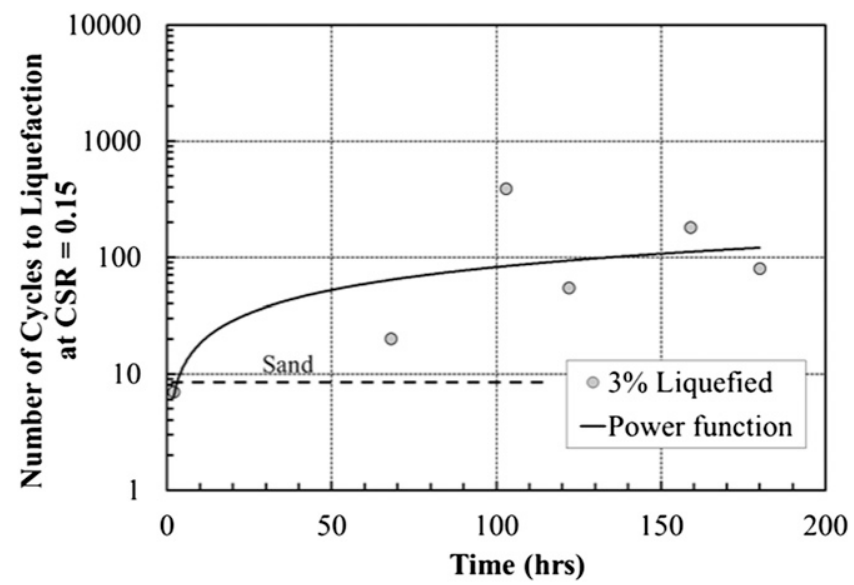

Fig. 3. Effect of hydration time on liquefaction resistance

in cyclic resistance relative to clean sand; however, there is an increased improvement in cyclic resistance with time allowed for hydration. The second point is consistent with the observation that a significant portion of the hydration stage $(\sim 72 \mathrm{~h}$ for the tests conducted in this research) must occur prior to application of the back-pressure for an increase in cyclic resistance to be observed. 


\section{Cyclic Resistance}

Figs. 1(b) and 2(b) show the decrease of effective confining stress with the number of cycles for the two tests on a 5\% sand-bentonite mixture. This decrease in effective stress is a result of the generation of excess mean pore pressure from one cycle to the next. Because both specimens were prepared in an identical manner except for the duration of the hydration stage, the pore pressure response per cycle must be related to the structure developed in the pore fluid. Fig. 4 plots the ratio of the excess cyclic pore pressure generated per cycle $\left(U_{\text {cyclic }}\right)$ to the deviatoric stress $\left(\sigma_{\text {deviatoric }}\right)$ applied versus hydration time. The ratio was taken during the period of steady decrease of the effective confining stresses [e.g., Fig. 1(b)]. During this time, the ratio was approximately constant until liquefaction, if it occurred. Fig. 4 shows that $U_{\text {cyclic }} / \sigma_{\text {deviatoric }}$ decreases substantially with the time allowed for hydration of the specimen before shearing. Once a critical hydration time is reached, the generation of excess cyclic pore pressures remains fairly constant and is on the order of 20-25\% of the deviatoric stress applied. As the excess cyclic pore pressure increases (at a given confining stress), the magnitude of excess mean pore pressure accumulated per cycle also increases and can eventually lead to liquefaction.

Another interesting aspect of the sand-bentonite mixture is its self-healing property. Fig. 5 shows the effective confining stress with the number of cycles for a $3 \%$ bentonite specimen subjected to two consecutive loading cycles with a 24-h resting period in between. For the first cyclic loading [Fig. 5(a)], the behavior was similar to that expected from a specimen that liquefies. After an initial period of fast reduction of the effective confining stress during the first cycles, a steady decrease rate followed until approximately Cycle 42. There was then a sharp decrease in confinement until the effective lateral stress was reduced to zero (a clean sand specimen would liquefy in 10 cycles under a CSR of 0.15 ). Following liquefaction, the excess pore pressure generated during cyclic shear was allowed to dissipate for at least $12 \mathrm{~h}$; cyclic loading was then applied to the same specimen at the same CSR (0.15). During the first cyclic loading stage, the axial strain was limited to $\pm 0.15 \%$ after the loss of effective stress to reduce specimen distortion and allow for performing the second loading. During the second cyclic loading of the specimen, liquefaction occurred at a similar number of cycles [Fig. 5(b)]. Similar results were observed in four additional tests. Fig. 5(c) shows the number of cycles to liquefaction during the second cyclic loading versus that during the first loading for all five specimens, and also shows that during the second cyclic loading all specimens were able to sustain the same or a greater number of

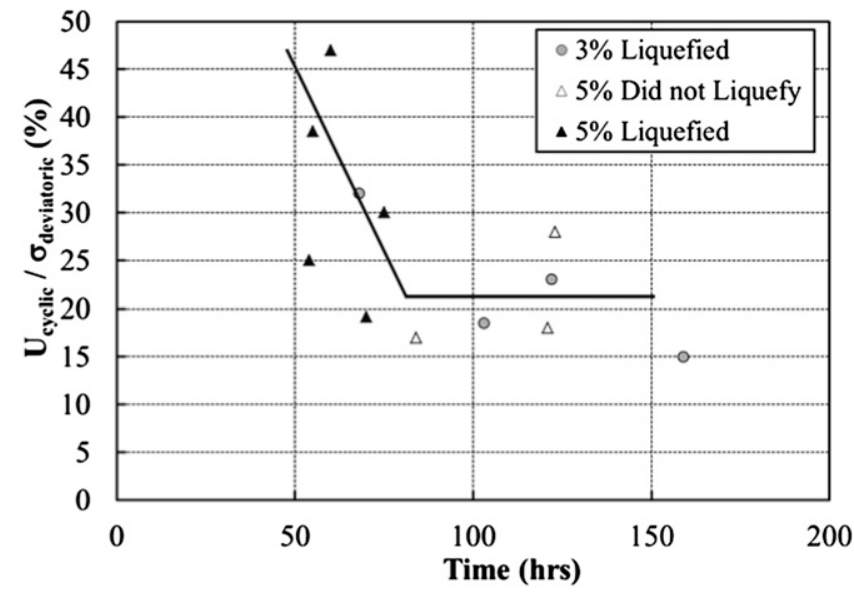

Fig. 4. Excess cyclic pore pressure generation with hydration time cycles before liquefying compared with the first loading. These results indicate that the treated sand can maintain its increased seismic resistance even after reaching liquefaction under a previous loading, which makes it an ideal field treatment method (no need for retreatment). These results are different from the findings reported by Seed et al. (1977), in that in these tests the specimens reached liquefaction under the first loading compared with a prestraining effect under the first loading in Seed et al. (1977).

Fig. 6 shows the cyclic resistance of the specimens with 3 and $5 \%$ bentonite by mass prepared using the following procedure: (1) the specimens were allowed to hydrate for $72 \mathrm{~h}$ after flushing with water; (2) they were back-pressure saturated for $24 \mathrm{~h}$; and (3) they were consolidated for another $24 \mathrm{~h}$. In Fig. 6, the results for clean sand are included for reference. The various symbols on the plot represent specimens that did liquefy, while the symbols with arrows across them represent specimens that did not liquefy after at least 500 cycles and were not generating any additional mean excess pore pressure. The solid lines represent the curves fitted through the 0,3 , and $5 \%$ bentonite specimens after 1 day of consolidation based on the following equation:

$$
\mathrm{CSR}(N f)=\mathrm{CSR}_{\min }+a N f^{-b}
$$

where $\operatorname{CSR}(N f)=\mathrm{CSR}$ required to generate liquefaction in $N f$ cycles; $N f=$ number of cycles to liquefaction; and $\mathrm{CSR}_{\min }, a$, and $b=$ fitting coefficients for a given bentonite content. The results show an order of magnitude increase in the number of cycles to reach liquefaction when $5 \%$ bentonite is added to the specimens; a slightly lower increase was found for specimens prepared with $3 \%$ bentonite.

Additional specimens with $3 \%$ bentonite were tested after 4 and 10 days of aging beyond the end of the consolidation stage to determine the change in cyclic resistance with aging time; the dashed lines through the $3 \%$ bentonite data at 4 and 10 days in Fig. 6 are drawn parallel to the trends observed in the tests with 1 day of aging. The data, also included in Fig. 6, show an order of magnitude gain in cyclic resistance after 4 days, and about two orders of magnitude gain is achieved if the specimens are tested after 10 days of postconsolidation aging. Only two tests were performed on $3 \%$ bentonite specimens after 10 days of aging.

Drnevich and Richart (1970) reported that for sands there is a threshold strain level below which no liquefaction takes place regardless of the number of loading cycles. This strain threshold corresponds to a CSR $\left(\mathrm{CSR}_{\min }\right)$ that is low enough such that there is little or no pore pressure buildup from one cycle to the next. Fig. 6 suggests that in the presence of bentonite, this threshold increases with increasing bentonite content and postconsolidation aging time. The minimum CSR required to generate liquefaction was found to be about $0.06,0.1$, and 0.145 for 0,3 , and $5 \%$ bentonite specimens after 1 day of consolidation, respectively; the values increased significantly with postconsolidation aging time to 0.2 for $3 \%$ bentonite specimens with 4-day consolidation and to 0.25 if the consolidation time was extended to 10 days. This increase in $\mathrm{CSR}_{\min }$ with time indicates that bentonite can be a practical solution for liquefaction mitigation in the field because the time between treatment and the occurrence of an earthquake is likely to be significantly longer than 10 days.

\section{Static Shear Strength}

A series of undrained isotropically consolidated static triaxial tests were performed to characterize the mechanical properties of the sand-bentonite mixtures and to determine the effects of bentonite on yield stress, stiffness, and steady-state behavior of the treated sand. The static triaxial specimens were prepared following the same 


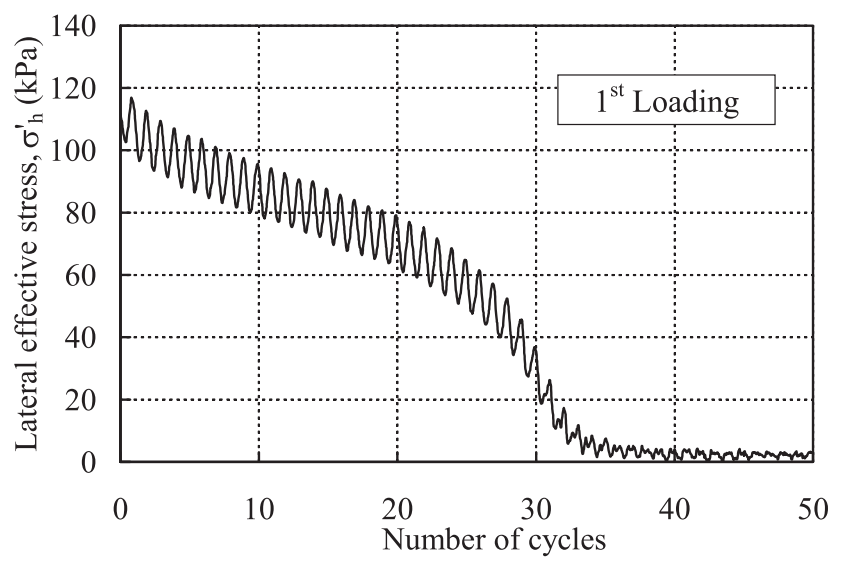

(a) first loading

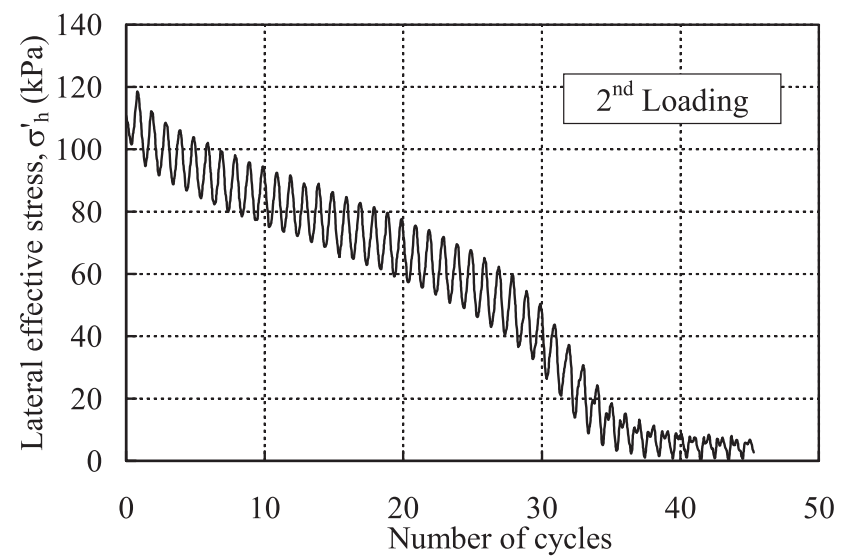

(b) second loading

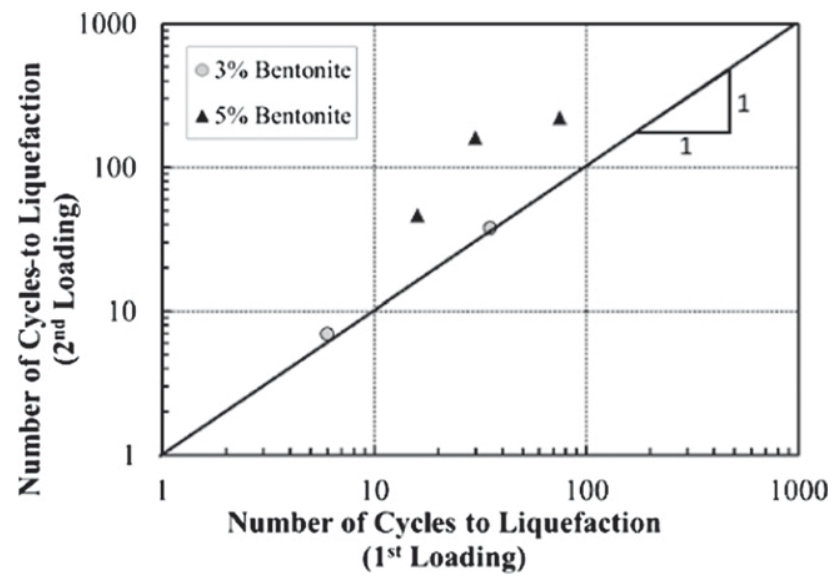

(c) first loading versus second loading

Fig. 5. Self-healing of sand-bentonite mixtures: (a) first loading; (b) second loading; (c) first loading versus second loading

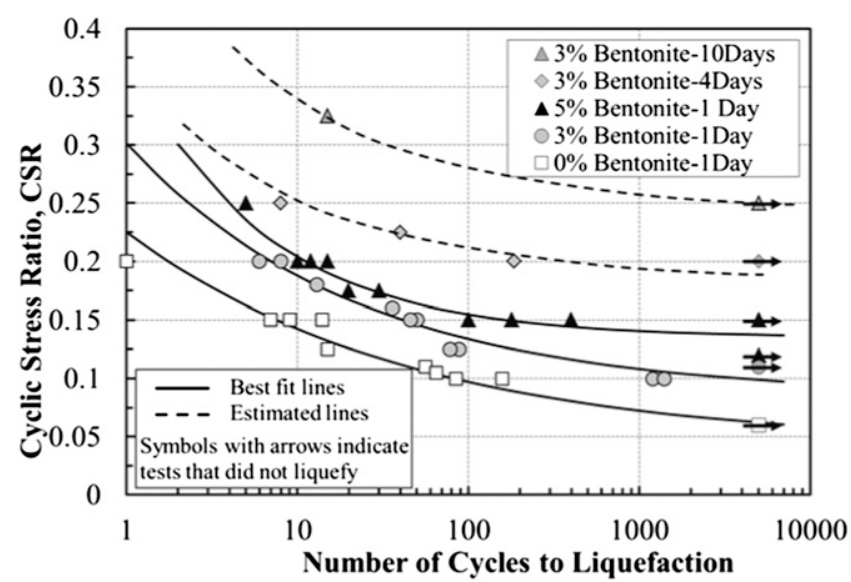

Fig. 6. CSR versus number of cycles to liquefaction

procedure used for the specimens tested under cyclic loading. The tests were run on specimens with 0,3 , and $5 \%$ bentonite content at 50,100 , and $200 \mathrm{kPa}$ confining stresses. Fig. 7 shows plots of the stress paths in the $p^{\prime}-q$ space. The stress paths are very similar to those typical of sand sheared in undrained triaxial compression. The stress paths start at a $45^{\circ}$ angle and then slowly shift to the left as the excess pore pressure builds up until the specimen reaches the yield state of stress; with further loading, the critical state or steady state is finally attained. The tests showed only a minor decrease in yield stress for specimens treated with bentonite (see Table 1). The maximum reduction in peak strength was around $13 \mathrm{kPa}$ with $5 \%$ bentonite. Additionally, the results show similar values for the critical-state friction angle for all three mixtures (differences within $1^{\circ}$ ). The failure envelopes drawn in correspondence to the yield stress values for specimens with bentonite show a cohesion intercept, likely a reflection of the presence of bentonite trapped between the sand grains. At higher strains (i.e., at the critical state), the grain-to-grain contacts are restored and no cohesion is measured. This notion is also supported by the results of the resonant column tests that showed a modest decrease in the small-strain shear modulus of the sand with treatment, as will be discussed subsequently.

Fig. 7 also includes, for comparison, the stress paths of three static triaxial tests conducted on sand specimens with $3 \%$ bentonite after postconsolidation aging periods of 4,7 , and 10 days. The results show that the aged specimens have the same critical-state failure envelope, and thus support the conclusions regarding the grain-tograin contact discussed. An interesting observation is that the specimens show a less contractive behavior with lower positive excess pore pressures compared with specimens with shorter consolidation times. This indicates that the specimens have an increased capacity with time of supporting undrained loading, which is consistent with the results obtained from the cyclic triaxial tests plotted in Fig. 6. 


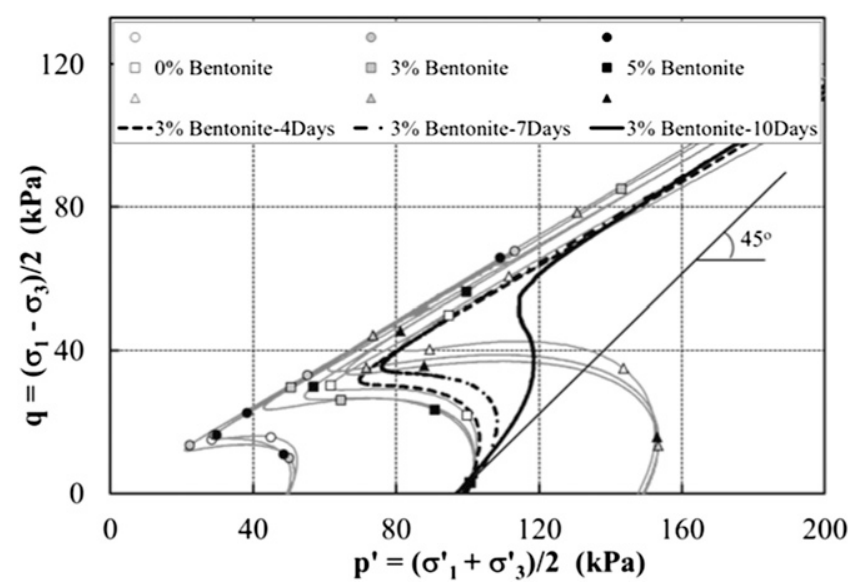

Fig. 7. $p^{\prime}-q$ curves for 0,3 , and $5 \%$ bentonite specimens

Table 1. Shear Strength Parameters at for 0,3 , and $5 \%$ bentonite specimens

\begin{tabular}{lccc}
\hline & \multicolumn{3}{c}{$\%$ Bentonite } \\
\cline { 2 - 4 } Shear strength parameter & $0 \%$ & $3 \%$ & $5 \%$ \\
\hline Critical state $c^{\prime}$ & $0 \mathrm{kPa}$ & $0 \mathrm{kPa}$ & $0 \mathrm{kPa}$ \\
Critical state $\varphi^{\prime}$ & $31^{\circ}$ & $31^{\circ}$ & $31^{\circ}$ \\
Yield stress $c^{\prime}$ & $0 \mathrm{kPa}$ & $4 \mathrm{kPa}$ & $5 \mathrm{kPa}$ \\
Yield stress $\varphi^{\prime}$ & $23^{\circ}$ & $18^{\circ}$ & $17^{\circ}$ \\
\hline
\end{tabular}

\section{Small-Strain Behavior}

Resonant column tests on clean Ottawa sand and sand with 3 and 5\% bentonite were performed under undrained conditions. Typically, resonant column tests are conducted drained, maintaining constant effective confining stress, to evaluate the variation of the shear modulus with shear strain. The tests were run undrained to observe if the shear strain threshold, at which specimens started to generate excess pore pressures, changed with the addition of bentonite. Fig. 8 shows plots of the shear modulus of clean sand specimens and specimens with sand mixed with 3 and $5 \%$ bentonite, tested after consolidation to 50,100 , and $193 \mathrm{kPa}$. Fig. 8 shows that at all stress levels the maximum shear modulus slightly decreases with the addition of bentonite. This is believed to be caused by the initial lubricating effect of the bentonite present between the sand grains. However, the differences are between 11 and 16\%. With increasing shearing strain, significant pore pressures were generated in the undrained tests. As a result, the effective confining stress of the specimen was substantially reduced, which caused a large decrease of the shear modulus of the soil. Such reduction was very dramatic compared with the drained tests.

Fig. 9 shows the excess pore pressures generated during the tests. For comparison, the shear modulus degradation is included. The pore pressures are normalized with respect to the effective confining stresses. The results indicate that, for the same effective confining stress, the excess pore pressure is generated much earlier in the clean sand specimens than in the treated specimens. For the same shearing strain, the magnitude of the excess pore pressures is much larger in clean sand than in treated sand. These findings are consistent with the observation that the linear threshold strain derived from the shear modulus curves increases with treatment. The results obtained indicate that the mobility of the sand grains is restrained by the bentonite gel, and thus the linear threshold is extended. The data are also consistent with observations from the cyclic triaxial tests.

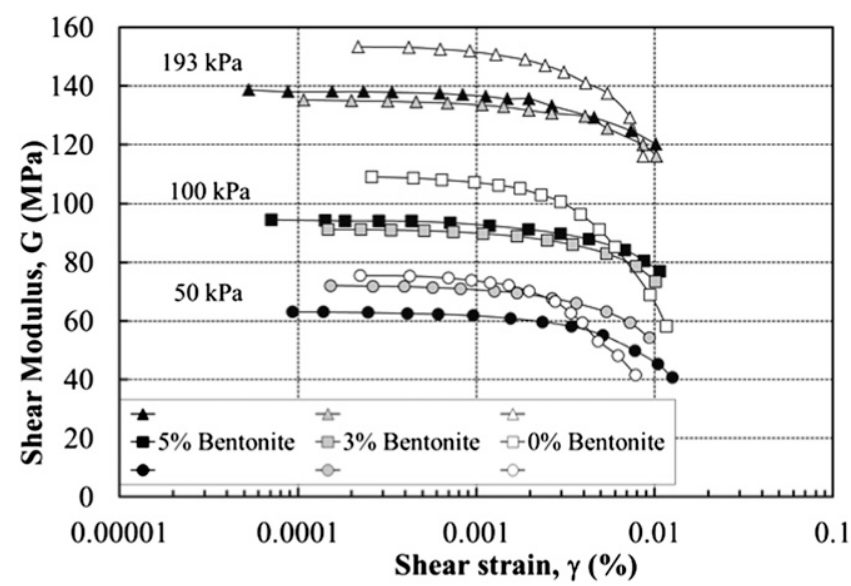

Fig. 8. Shear modulus versus shear strain 0,3 , and $5 \%$ bentonite specimens (El Mohtar et al. 2008a)

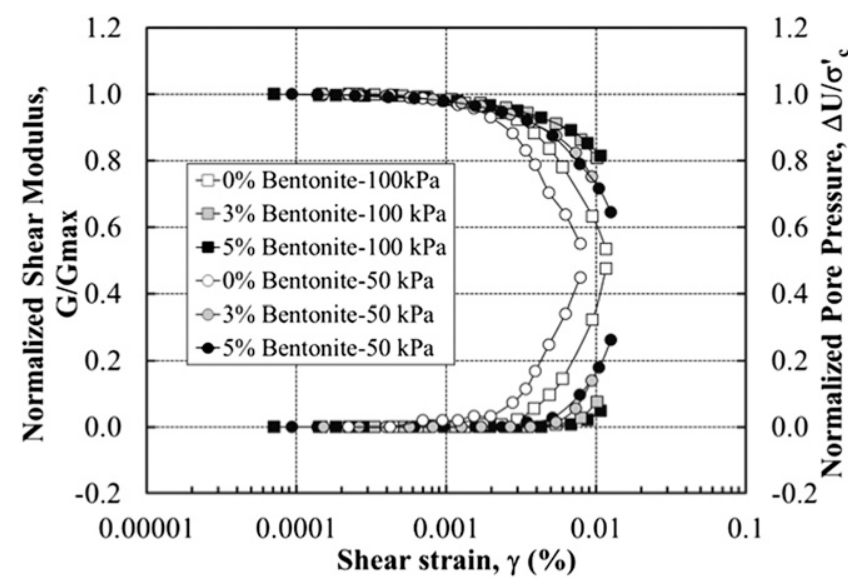

Fig. 9. Normalized shear modulus and excess pore pressure versus shear strain 0,3 , and $5 \%$ bentonite specimens

\section{Results from Sand Specimens Permeated with Bentonite}

\section{Rheological Properties of Bentonite Suspensions}

A critical objective of the project was the development of a technique to treat bentonite with a chemical compound that delays gelling of the bentonite particles in an aqueous medium, and thus decreases the initial viscosity of the water-bentonite suspension, allowing its permeation in a soil medium. The reduced initial gelling needs to be temporary such that, with time (postpermeation), the bentonite can gel inside the soil pores and develop the structure needed for the treatment to be effective. The addition of SPP to concentrated bentonite suspensions was found to be successful in achieving these results. It decreased the initial viscosity of the concentrated suspension, allowing its permeation in the sand medium; however, with time, the suspension recovered the properties typical of the untreated material.

SPP is a polyphosphate with a chemical formula of $\mathrm{Na}_{4} \mathrm{P}_{2} \mathrm{O}_{7}$. Polyphosphates are salts composed of chains in which each phosphate atom is linked to its neighbors through two oxygen atoms, thus forming a linear, unbranched structure. The general formula is $\mathrm{M}(n+2) \mathrm{P} n \mathrm{O}(3 n+1)$, where $\mathrm{M}=$ metal and $n=$ degree of 
polymerization. SPP is a dimeric form $(n=2)$ and its molecular structure consists of two $\mathrm{PO}_{4}$ tetrahedral units sharing a common oxygen (Schofield and Samson 1954; Asher and Bar-Yosef 1982).

The viscosity of bentonite clay suspensions is, in part, a result of the negatively charged faces of clay particles interacting with positively charged edge surfaces (Brandenburg and Lagaly 1988). Pyrophosphate has a high affinity for the broken edge sites of clay minerals because it has the unique ability to form covalent bonds on broken edge sites of clay minerals such as bentonite. Pyrophosphate has a strongly negative charge, and when chemically grafted to the edges of clay particles it imparts an overall negative charge to the edge sites that reduces edge-to-face contacts, thus creating a highly dispersed solution with reduced viscosity. The result is that treatment of bentonite with SPP greatly reduces the viscosity of the clay suspension (Clarke 2008). However, with time the viscosity of the clay increases and the clay suspension recovers the solidlike properties typical of untreated bentonite concentrated suspensions (Clarke 2008). While the mechanism for this recovery is not completely understood, one hypothesis is that over time SPP undergoes a hydrolysis process where the dimeric SPP converts into a monomeric orthophosphate.

The transition in behavior with time of SPP-treated bentonite suspensions is illustrated in Fig. 10, which presents data obtained from amplitude sweep tests in an Anton Paar 301 rheometer on $10 \%$ bentonite suspensions treated with $0 \%$ (reference untreated suspension), $0.1,0.5$, and $1 \%$ SPP (by mass of the bentonite). The $10 \%$ bentonite concentration corresponds to the concentration of the clay suspension formed in the pore space of a sand specimen prepared with $3 \%$ bentonite by dry mass of the sand at $35 \%$ skeletal relative density. Hence, the rheology of the suspension can be considered representative of the behavior of the pore fluid formed in the drymixed sand-bentonite specimens.

In amplitude sweep tests, a specimen is subjected to an oscillatory shear strain $\left[\gamma=\gamma_{0} \sin (\omega t)\right]$ of increasing amplitude, $\gamma_{0}$, at constant frequency while measuring the resulting time-dependent stress. The stress can be expressed as the sum of an elastic component in phase with the strain and a viscous component out of phase with the strain; i.e., $\tau=\gamma_{0}\left\{G^{\prime} \sin (\omega t)+G^{\prime \prime} \cos (\omega t)\right\}$, where $G^{\prime}$ and $G^{\prime \prime}$ are the storage modulus and loss modulus, respectively (e.g., Barnes et al. 1989). Fig. 10 shows how the storage modulus $\left(G^{\prime}\right)$, the elastic component of the modulus, of the SPP-treated suspensions measured at low shear strains changes with time. Specifically, Fig. 10 shows that at early times the magnitude of the storage modulus is greatly influenced by the dosage of SPP, with a more

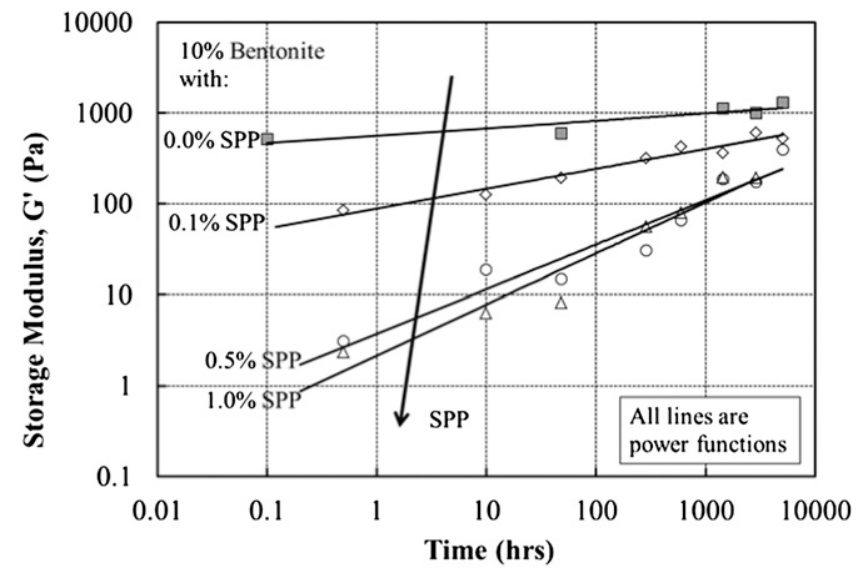

Fig. 10. Storage modulus of $10 \%$ bentonite suspensions treated with SPP (data from Clarke 2008) than two orders of magnitude decrease in $G^{\prime}$ with the addition of 0.5 and $1 \%$ SPP. For all SPP-treated suspensions, $G^{\prime}$ increases with time, with the rate of recovery of the modulus decreasing with increasing SPP dosage. Ultimately, given enough time, the storage modulus of the suspensions with SPP approaches that of the untreated bentonite. This is consistent with the large decrease in liquefaction potential of sand specimens permeated with bentonite treated with SPP, as discussed subsequently.

\section{Permeation Tests}

Two rigid wall permeameters were designed to fulfill the following two specific needs in this project: (1) determine the dosage of SPP required to allow permeation of a concentrated bentonite suspension into clean sand; and (2) measure the length of permeation into the sand. The two permeameters were identical except for their length. The first permeameter was $0.3-\mathrm{m}$ long. The second permeameter was $0.9-\mathrm{m}$ long and was used to determine the distance the bentonite suspension could penetrate into the sand. To limit pressure-filtration problems and provide uniform delivery of the suspension through the cross section, porous stones and filter paper were replaced by a three-layered filter. The bottom filter consisted of three layers: a geogrid with 1-mm openings; a center with $2 \mathrm{~cm}$ of fine aggregate (9.53-6.35 mm); and a top with $2 \mathrm{~cm}$ of fine aggregate (9.53-6.35 $\mathrm{mm}$ ) and the top with $2 \mathrm{~cm}$ of coarse sand (6.35-1.27 $\mathrm{mm})$. The filter at the top of the permeameter was identical to the base filter but with the three layers placed in reverse order. The sand to be permeated was air-pluviated using a funnel connected to a pluviation tube with zero drop height.

The permeation tests were performed with a $10 \%$ bentonite suspension. Most tests were performed using the 0.3 -m-long tube to initially determine what suspensions could permeate the selected sand medium; $10 \%$ suspensions with 0.5 and $1 \%$ SPP were effective in uniformly permeating the entire $0.3-\mathrm{m}$-long sand specimen (this was ascertained through hydrometer tests conducted on different portions of the sand column). The tests on the 0.9-m-long permeameter indicated that a $10 \%$ bentonite suspension could be permeated at least $45 \mathrm{~cm}$ into the sand column if treated with $0.5 \%$ SPP. These tests demonstrate the feasibility of permeating a sand deposit with concentrated bentonite suspensions treated with SPP; however, additional tests will be needed to determine the optimum SPPbentonite combination for a specific site and treatment scheme.

\section{Cyclic Resistance}

Based on the permeameter results, a $10 \%$ bentonite suspension treated with $0.5 \%$ SPP was selected to permeate the sand specimens to be tested in the cyclic triaxial apparatus. As discussed previously, $10 \%$ bentonite suspensions were selected for this study based on the volumetric calculations of the volume of water filling the voids of a $3 \%$ dry-mixed sand bentonite specimen prepared at a skeleton relative density of $35 \%$ and the weight of bentonite present in the specimen. The specimens were permeated outside the triaxial setup and then transferred to the triaxial cell for back-pressure, consolidation, and shearing. The external permeation setup included a filter material (similar to the one described for the permeation tests) to ensure uniform distribution of the suspension inside the sand specimen. However, this resulted in less control over the initial skeletal relative density, with the result that the permeated specimens had a lower relative density than the dry-mixed specimens (20\% skeleton relative density for permeated specimens compared with $35-40 \%$ for the dry-mix specimens). Additional cyclic triaxial tests were performed on clean sand specimens at a $20 \%$ relative density to provide a reference baseline for the clean sand. 


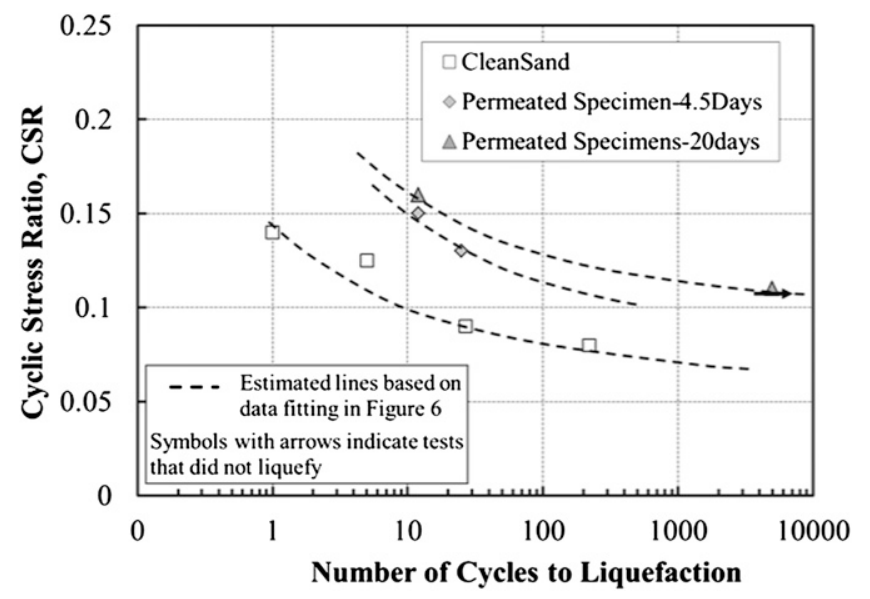

Fig. 11. CSR versus number of cycles to liquefaction for permeated specimens

Fig. 11 shows the results of the clean sand and the permeated specimens tested after postconsolidation rest periods of 4.5 and 20 days. The curves for the permeated specimens are drawn parallel to the curves in Fig. 6. The results show an order of magnitude increase in the number of cycles to liquefaction after 4.5 days. The specimen tested after 20 days of postconsolidation aging at a CSR of 0.11 did not liquefy after 340 cycles, at which point no additional excess pore pressure was being generated. This indicates that an increase of the minimum CSR is required to produce liquefaction. The 5\% double-amplitude strain was used as the criterion for liquefaction for all the results presented in Fig. 11. This was necessary because of the low permeability of the permeated specimens, which resulted in delayed pore pressure detection. After each cyclic test was completed, the specimens were taken apart and the bentonite content was determined at the top, center, and bottom using hydrometer analyses. The percentage of bentonite across the height of all specimens tested ranged between 3 and $3.6 \%$ by mass of the sand, indicating that the permeation method produced a fairly uniform distribution of bentonite in the specimen.

Fig. 12 shows a comparison of the increase in cyclic resistance over time between specimens permeated with $10 \%$ bentonite suspensions treated with $0.5 \%$ SPP and specimens prepared with the dry-mix method. The CRR values are defined as the CSR causing liquefaction in 20 cycles. Fig. 12 shows the CRR values normalized by the CRR of clean sand to account for the difference in the relative densities of the two preparation methods. The CRR of the permeated specimens was 1.5 times that of clean sand after $250 \mathrm{~h}$ (10 days) of postconsolidation aging and kept increasing with time. Fig. 12 also shows that the dry-mix specimens have larger CRR with postconsolidation aging time than the permeated specimens. The lower CRR measured in the permeated specimens is consistent with the retarded storage modulus buildup with time in the presence of SPP, as seen in Fig. 10. Although a full recovery of the properties of the suspension may never be reached, or at least may take a very long time, the CRR of the permeated specimens is expected to continue increasing.

\section{Linking Mechanical Behavior to Microstructure}

The data for both dry-mixed and permeated sand bentonite specimens reported previously demonstrate that the presence of bentonite increases the cyclic resistance of sand. The role played by hydration duration (Fig. 3) and aging time (Fig. 6) suggests that the increase

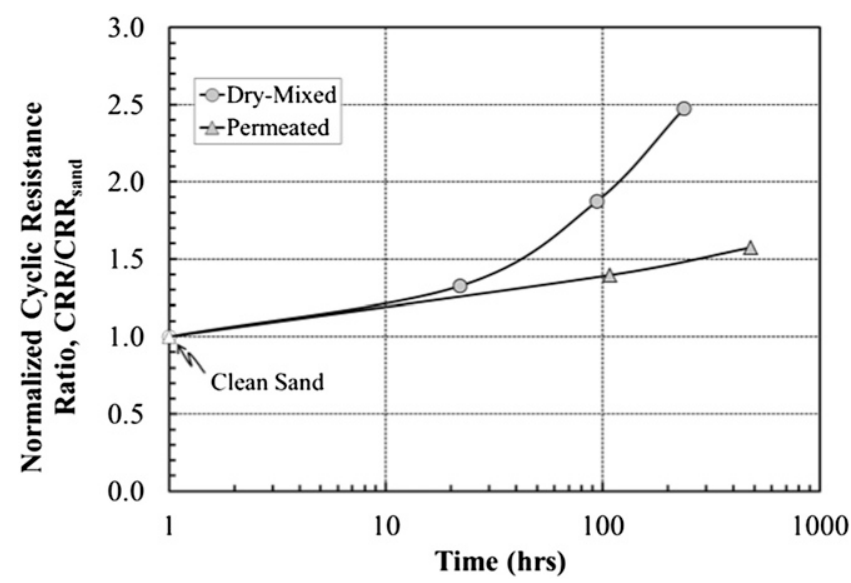

Fig. 12. Increase of CRR with time for $3 \%$ bentonite dry-mixed specimens and for specimens permeated with $10 \%$ bentonite and $0.5 \%$ SPP suspension

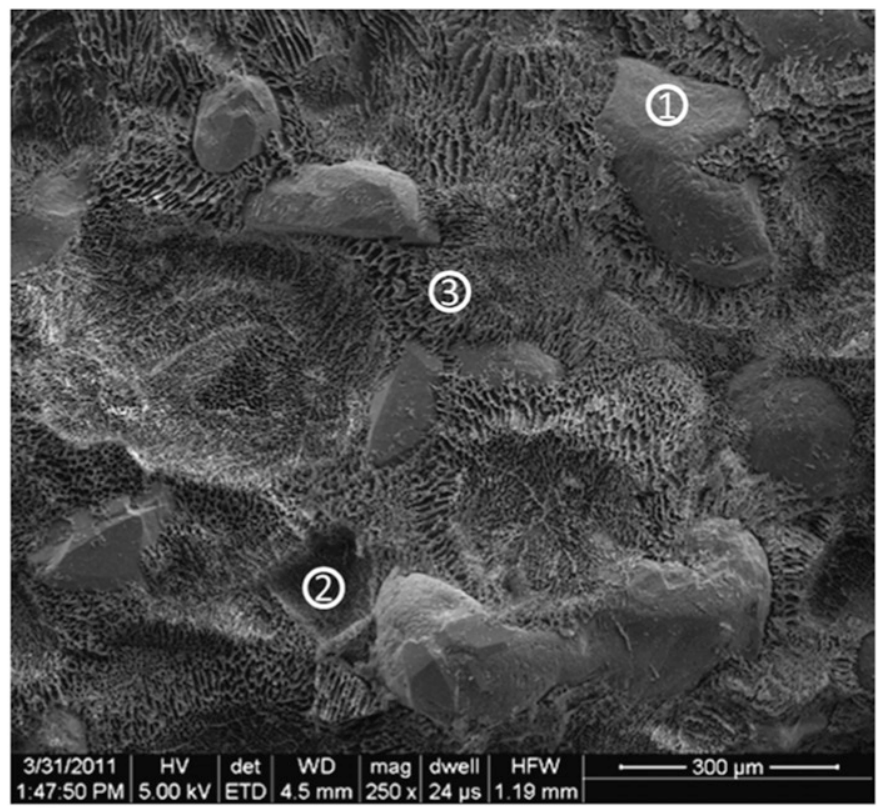

(1): sand Grain

(2): imprint of a sand grain in the bentonite suspension

(3): bentonite suspension

Fig. 13. Cryo-SEM image of a dry-mixed sand bentonite specimen (courtesy of El Howayek 2011)

in liquefaction resistance can be ascribed to the formation of a pore fluid that consists of a concentrated bentonite suspension. This conclusion is also supported by the increase in cyclic resistance observed in the specimens permeated with bentonite suspensions treated with SPP (Figs. 11 and 12) because the rheology of the pore fluid evolves with time (Fig. 10).

Direct insight into the microstructure of the sand bentonite specimens can be gained using cryo-scanning electron microscopy (cryo-SEM), in which a specimen is imaged following freezing rather than drying. This technique is especially suited for imaging water-rich materials such as the pore fluid formed in the presence of bentonite, in which the water itself is an essential part of the structure. Fig. 13 shows a cryo-SEM image obtained by El Howayek 


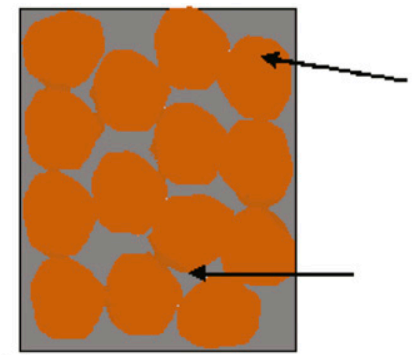

(a) Permeated specimen

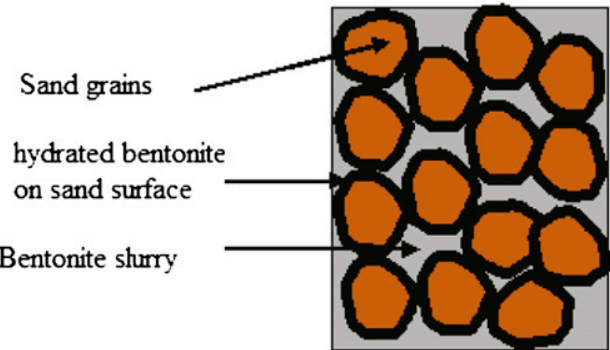

(b) Dry mixed specimen

Fig. 14. Schematic of microstucture of (a) permeated specimen; (b) dry-mixed sand-bentonite specimen

(2011) for a dry-mixed sand-bentonite specimen. To obtain the image, a small sand-bentonite sample was first plunged into a liquid nitrogen slush and then transferred to a Gatan Alto 2500 prechamber, where it was cooled to about $-160^{\circ} \mathrm{C}$. This ultrarapid freezing process inhibits the formation of crystalline ice, which would cause distortion of the structure. After sublimation for $15 \mathrm{~min}$ at $-85^{\circ} \mathrm{C}$ to remove unbound water, and sputter coating with platinum, the sample was imaged with a FEI NOVA nano-SEM field-emission SEM using an Everhart-Thornley detector (Everhart and Thornley 1960) detector. Fig. 14 shows the sand grains with the voids in between filled with the bentonite gel. Consistent with the observations from the cryo-SEM images of bentonite gels obtained by Solomon (2006), the image shows that the gel between the sand grains has a cellular structure with size (on the order of microns) that greatly exceeds the size of the bentonite particles. The existence of this long-range order is typical of gels formed when attractive forces between the particles are predominant, and which exhibit rheological behavior consistent with that measured in the amplitude sweep tests reported previously.

In discussing the microstructure it is worth noting that despite the consistent picture in terms of cyclic response for both dry-mixed and permeated specimens, these two types of specimens are bound to have slightly different microstructure. Specifically, as illustrated in Fig. 14, in the case of the dry-mixed specimens, given that the bentonite is introduced during formation of the specimens, inevitably some of the clay will be trapped at the sand contacts, and some may adhere to the sand particles. As suggested by Fig. 14(b), this may lead to the formation of a thin layer of hydrated bentonite that does not contribute to the pore fluid. This hypothesis is supported by the results of the resonant column and monotonic triaxial tests on dry-mixed specimens reported previously. These data show a slight decrease in $G_{\max }$ and in the peak friction angle in the presence of bentonite. Additional support for this hypothesis is provided by the measurements of $G_{\max }$ with aging time conducted by El Mohtar et al. (2008b) with the resonant column. These data show a greater increase of the stiffness with time in the sand-bentonite mixtures relative to the clean sand, confirming the presence of plastic material between the sand grains. The resonant column data for the dry-mixed specimens presented previously also indicate that the amount of bentonite trapped at the particle contacts is relatively small because the difference in values of $G_{\max }$ between the clean sand specimens and specimens with bentonite is reduced as the consolidation stress increases. Similarly, the static triaxial tests show consistent values of the critical-state angle, indicating that after sufficient straining the grain-to-grain contacts are restored.

Overall, the aforementioned results suggest that despite the small differences in microstructure existing between the dry-mixed and permeated specimens, many of the conclusions drawn from the extensive experimental program on dry-mixed specimens (e.g., the effect of clay concentration and aging time on cyclic resistance) can be extended to the permeated specimens, which more closely represent the conditions in which the treatment would be deployed in the field. Moreover, the results also suggest that the small reduction in stiffness and yield strength observed for the dry-mixed specimens would likely not be observed in the field, where the bentonite would be delivered through permeation. This hypothesis is supported by static triaxial data reported by Rugg et al. (2011) for sand specimens permeated with SPP-treated bentonite suspensions similar to those examined in this study. These data show minimal change $\left(1^{\circ}\right)$ in the peak friction angle of the permeated sand-bentonite specimens relative to the clean sand.

\section{Conclusions}

This paper presents the results of resonant column, undrained static and cyclic triaxial tests performed on dry-mixed sand-bentonite specimens with 0,3 , and $5 \%$ bentonite by dry mass of sand and of undrained cyclic triaxial tests on sand specimens permeated with $10 \%$ bentonite suspensions treated with $0.5 \%$ SPP by weight. The cyclic triaxial tests show that for dry-mixed sand specimens tested at the same skeleton relative density and same CSR the percentage of bentonite and the degree of hydration of the bentonite inside the sand pore space are the critical factors controlling cyclic resistance. The specimens with sufficient hydration time showed a 10 -fold increase in cyclic resistance compared with the clean sand specimens. For the same CSR and skeleton relative density, the number of cycles to liquefaction increased with the aging time of the bentonite inside the pores.

The increase in liquefaction resistance can be ascribed to the formation of a bentonite gel in the pore space, which causes an increase of the elastic threshold of the sand, reduces the excess pore pressure generated during cycles of loading, and restrains the motions of the sand grains during cyclic loading. Direct evidence of the formation of this gel is provided by cryo-SEM images. The influence of the pore fluid on the cyclic resistance was further confirmed by cyclic triaxial tests on sand specimens permeated with a $10 \%$ bentonite suspension and $0.5 \%$ SPP. These tests showed a 10-fold increase in the number of cycles to liquefaction with respect to clean sand, with the cyclic resistance increasing with time. This treatment of liquefaction is self-healing because the treated sand is able to rebuild its resistance after a delay of at least $12 \mathrm{~h}$ beyond the first loading.

The tests conducted on dry-mixed specimens indicate that the presence of bentonite caused a small reduction in stiffness and strength of the sand under working loads. These reductions are associated with the procedure followed to prepare the dry-mixed specimens, and are not expected to be observed in the field where the bentonite would be delivered through permeation. 
The work conducted also shows that the rheology of concentrated bentonite suspensions can be engineered to allow their delivery through permeation. Specifically, with the addition of $0.5 \%$ SPP by mass of clay, the viscosity of a $10 \%$ bentonite suspension initially decreased to a value that allowed permeation of the suspension into the sand, while over time the modified bentonite suspension recovered the gel structure that ensures its effectiveness in increasing the cyclic resistance of the sand.

\section{Acknowledgments}

This research was supported by the National Science Foundation, Geomechanics and Geotechnical Systems Program, under Grant No. CMS-0408739. This support is gratefully acknowledged. Special thanks go to Julia P. Clarke for her work on the rheology of bentonite suspensions and Alain El Howayek for sharing the cyro-SEM picture of the dry-mix sand-bentonite specimen.

\section{References}

Asher, L. E., and Bar-Yosef, B. (1982). "Effects of pyrophosphate, EDTA, and DTPA on zinc sorption by montmorillonite." Soil Sci. Soc. Am. J., 46(2), 271-276.

Barnes, H. A., Hutton, J. F., and Walters, K. (1989). An introduction to rheology, Elsevier, Amsterdam, Netherlands.

Brandenburg, U., and Lagaly, G. (1988). "Rheological properties of sodium montmorillonite dispersions." Appl. Clay Sci., 3(3), 263-279.

Carraro, J. A. H., Bandini, P., and Salgado, R. (2003). "Liquefaction resistance of clean and nonplastic silty sands based on cone penetration resistance.” J. Geotech. Geoenviron. Eng., 129(11), 965-976.

Chang, N. Y., Yeh, S. T., and Kaufman, L. P. (1982). "Liquefaction potential of clean and silty sands." Proc., 3rd Int. Earthquake Microzonation Conf., Seattle, Vol. 2, Dept. of Civil Engineering, Univ. of Washington, Seattle, 1017-1032.

Clarke, J. (2008). "Investigation of time-dependent rheological behavior of sodium pyrophosphate-bentonite suspension." M.S. thesis, Purdue Univ., West Lafayette, IN.

De Alba, P., Seed, H. B., and Chan, C. K. (1976). "Sand liquefaction in largescale simple shear tests." J. Geotech. Engrg. Div., 102(9), 909-927.

Dezfulian, H. (1982). "Effects of silt content on dynamic properties of sandy soils." Proc., 8th World Conf. on Earthquake Engineering, Earthquake Engineering Research Institute, Oakland, CA, 63-70.

Dobry, R., Stokoe, K. H., II, Ladd, R. S., and Youd, T. L. (1981). "Liquefaction susceptibility from $S$-wave velocity." Proc., ASCE National Convention, Preprint 81-544, ASCE, New York.

Drnevich, V. P., and Richart, F. E., Jr. (1970). "Dynamic prestraining of dry sand." J. Soil Mech. and Found. Div., 96(2), 435-469.

El Howayek, A. (2011). "Characterization, rheology and microstructure of laponite." M.S. thesis, Purdue Univ., West Lafayette, IN.

El Mohtar, C. S. (2008). "Pore fluid engineering: An auto-adaptive design for liquefaction mitigation." Ph.D. dissertation, Purdue Univ., West Lafayette, IN.

El Mohtar, C. S., Clarke, J., Bobet, A., Santagata, M., Drnevich, V., and Johnston, C. (2008a). "Cyclic response of sand with thixotropic pore fluid." Proc., 6th ASCE Geotechnical Earthquake Engineering and Soil Dynamics Conf., Geotechnical Special Publication 181, ASCE, New York.

El Mohtar, C. S., and Rugg, D. (2011). "New three-way split mold design and experimental procedure for testing soft, grouted soils." ASTM Geotech. Test. J., 34(6), 365-371.

El Mohtar, C. S., Santagata, M., Bobet, A., Drnevich, V., and Johnston, C. (2008b). "Effect of plastic fines on the small strain stiffness of sand." Proc., 4th Int. Symp. on Deformation Characteristics of Geomaterials (IS-Atlanta), Vol. 1, IOS, Amsterdam, Netherlands, 245-251.

Everhart, T. E., and Thornley, R. F. M. (1960). "Wide-band detector for micro-microampere low-energy electron currents." J. Sci. Instrum., $37(7), 246-258$.
Finn, W. L., Ledbetter, R. H., and Wu, G. (1994). "Liquefaction in silty soils: Design and analysis." Proc., Ground Failures under Seismic Conditions, Geotechnical Special Publication 44, ASCE, New York, 51-76.

Gallagher, P. (2000). "Passive site remediation for mitigation of liquefaction risk.” Ph.D. dissertation, Virginia Tech, Blacksburg, VA.

Gallagher, P. M., Conlee, C. T., and Rollins, K. M. (2007). "Full-scale field testing of colloidal silica grouting for mitigation of liquefaction risk." J. Geotech. Geoenviron. Eng., 133(2), 186-196.

Gallagher, P. M., and Mitchell, J. K. (2002). "Influence of colloidal silica grout on liquefaction potential and cyclic undrained behavior of loose sand." Soil Dyn. Earthquake Eng., 22(9-10), 1017-1026.

Georgiannou, V. N., Hight, D. W., and Burland, J. B. (1991). "Behaviour of clayey sands under undrained cyclic triaxial loading." Geotechnique, 41(3), 383-393.

Haldavnekar, V., Bobet, A., Santagata, M., and Drnevich, V. (2003). "Soil treatment with a thixotropic fluid: An autoadaptive design for liquefaction prevention." Proc. 11th Int. Conf. on Soil Dynamics and Earthquake Engineering and 3rd Int. Conf. on Earthquake Geotechnical Engineering, Soil. Dyn. Earthquake Eng., 26(II), 553-560.

Ishihara, K. (1993). "Liquefaction and flow failure during earthquakes." Geotechnique, 43(3), 351-415.

Ishihara, K. (1996). Soil behaviour in earthquake geotechnics, 1st Ed., Claredon, Oxford, U.K.

Ishihara, K., and Koseki, J. (1989). "Discussion of cyclic shear strength of fines-containing sands." Proc., 12th Int. Conf. on Soil Mechanics and Foundation Engineering, Int. Society of Soil Mechanics and Geotechnical Engineering, London, 101-106.

Ishihara, K., and Yamazaki, F. (1980). "Cyclic simple shear test on saturated sand in multi-directional loading." Soils Found., 20(1), 45-59.

Ishihara, K., and Yasuda, S. (1975). "Sand liquefaction in hollow cylinder torsion under irregular excitation." Soils Found., 15(1), 45-59.

Koester, J. P. (1994). "The influence of fine type and content on cyclic strength." Proc., Ground Failures under Seismic Conditions, Geotechnical Special Publication 44, ASCE, New York, 17-33.

Komine, H., and Ogata, N. (2003). "New equations for swelling characteristics of bentonite-based buffer materials." Can. Geotech. J., 40(2), 460-475.

Kuerbis, R., Negussey, D., and Vaid, V. P. (1988). "Effect of gradation and fines content on the undrained response of sand." Proc., Hydraulic Fill Structures Symp., Fort Collins, CO, 330-345.

LabVIEW 7.1 [Computer software]. Austin, TX, National Instruments.

Law, K. T., and Ling, Y. H. (1992). "Liquefaction of granular soils with noncohesive and cohesive fines." Proc., 10th World Conf. on Earthquake Engineering, Rotterdam, Taylor \& Francis, London, 1491-1496.

Martin, J., and Olgun, C. G. (2006). "Liquefaction mitigation using jet-grout columns-1999 Kocaeli earthquake case history." Proc., Sessions of GeoShanghai, ASCE, Reston, VA, 349-358.

Mohamad, R., and Dobry, R. (1983). "Discussion of effect of static shear on resistance to liquefaction by vaid and chern." Soils Found., 23(4), 139-143.

Olgun, C. G. (2003). "Performance of improved ground and reinforced soil structures during earthquakes-Case studies and numerical analyses." $\mathrm{Ph} . \mathrm{D}$. thesis, Virginia Tech, Blacksburg, VA.

Polito, C. P. (1999). "The effects of non-plastic and plastic fines on the liquefaction of sandy soils." Ph.D. thesis, Virginia Tech, Blacksburg, VA.

Polito, C. P., and Martin, J. R., II. (2003). "A reconciliation of the effects of non-plastic fines on the liquefaction resistance of sands reported in the literature." Earthquake Spectra, 19(3), 635-651.

Poulos, S. J., Castro, G., and France, J. W. (1985). "Liquefaction evaluation procedure." J. Geotech. Engrg., 111(6), 772-791.

Rugg, D. A., Yoon, J., Hwang, H., and El Mohtar, C. S. (2011). "Undrained shearing properties of sand permeated with a bentonite suspension for static liquefaction mitigation." Proc., Geofrontiers, ASCE, Reston, VA.

Schofield, R. K., and Samson, H. R. (1954). "Flocculation of kaolinite due to the attraction of oppositely charged crystal faces." Discuss. Faraday Soc., 18(18), 135-145.

Seed, H. B., Chan, C. K., and Mori, K. (1977). "Influence of seismic history on the liquefaction of sands." J. Geotech. Engrg. Div., 103(4), 257-270.

Seed, H. B., Idriss, I. M., and Arango, I. (1983). "Evaluation of liquefaction potential using field performance data." J. Geotech. Engrg., 109(3), $458-482$. 
Seed, H. B., and Lee, K. L. (1966). "Liquefaction of saturated sands during cyclic loading." J. Soil Mech. and Found. Div., 92(6), 105-134.

Seed, H. B., Tokimatsu, K., Harder, L. F., and Chung, R. M. (1985). "The influence of SPT procedures in soil liquefaction resistance evaluations." J. Geotech. Engrg., 111(12), 1425-1445.

Shen, C. K., Vrymoed, J. L., and Uyeno, C. K. (1977). "The effects of fines on liquefaction of sands." Proc., 9th Int. Conf. on Soil Mechanics and Foundation Engineering, Vol. 2, Springer, NY, 381-385.

Solomon, W. (2006). "Investigations of microstructure in aqueous colloid dispersions: Na-montmorillonite as a case material." M.S. thesis, Purdue Univ., West Lafayette, IN.

Spagnoli, G. (2008). "Theoretical evaluations of liquefaction mitigation through jet grouting." Geotech. News, 26(3), 41-45.

Thevanayagam, S., Shenthan, T., Mohan, S., and Liang, J. (2002). "Undrained fragility of clean sands, silty sands, and sandy silts." J. Geotech. Geoenviron. Eng., 128(10), 849-859.

Tokimatsu, K., and Yoshimi, Y. (1983). "Empirical correlation of soil liquefaction based on SPT $N$-value and fines content." Soils Found., 23(4), 56-74.
Tronsco, J. H., and Verdugo, R. (1985). "Silt content and dynamic behavior of tailing sands." Proc., 12th Int. Conf. on Soil Mechanics and Foundation Engineering, Taylor \& Francis, London, 1311-1314.

Vaid, V. P. (1994). "Liquefaction of silty soils." Proc., Ground Failures under Seismic Conditions, Geotechnical Special Publication 44, ASCE, New York, 1-16.

Vaid, Y. P., and Chern, J. C. (1983). "Effect of static shear on resistance to liquefaction." Soils Found., 23(1), 47-60.

Wang, W. (1979). "Some findings in soil liquefaction." Research Rep., Water Conservancy and Hydroelectric Power Scientific Research Institute, Beijing.

Yamamuro, J. A., and Wood, F. M. (2004). "Effect of depositional method on the undrained behavior and microstructure of sand with silt." Soil Dyn. Earthquake Eng., 24(9-10), 751-760.

Yasuda, S., Wakamatsu, K., and Nagase, H. (1994). "Liquefaction of Artificially Filled Silty Sands.” Proc., Ground Failures under Seismic Conditions, Geotechnical Special Publication 44, ASCE, New York, 91-104.

Youd, T. L., et al. (2001). "Liquefaction resistance of soils: Summary report from the 1996 NCEER and 1998 NCEER/NSF workshop on evaluation of liquefaction resistance of soils." J. Geotech. Geoenviron. Eng., 127(10), 817-833. 